\title{
Performance Analysis of Thermo Electric Generator using MATLAB
}

\author{
Sreekala P, A Ramkumar, K.Rajesh,
}

\begin{abstract}
In this paper discussed with the mathematical model of thermo electric generator. Designed each blocks based on mathematical equation and by using the equations they are connected and verified the output. The peak energy is achieved when the internal resistance of the TEG is equal to the resistance of the load. In order to increase the existing transport,voltage carrying and power rating the thermo electric generators are connected in series, parallel or series -parallel connections. The mathematical model is simulated in matlab and the results are verified.
\end{abstract}

Keywords : Thermo Electric Generator, Thermal Conductivity, Voltage, Current

\section{INTRODUCTION}

The thermo electric is solid state energy converting device working with Seebeck effect .Power generation using thermo electric method is clean energy.. Electricity is produced by the keeping thermo electric generator in flat plate or curved surface. Thermoelectric module converts the difference in temperature between the top and bottom surface of the module to electric energy directly. Thermo electric module is classified into two thermo electric generators and thermo electric coolers .Thermo electric coolers works on the principle of Peltier effect. In this system there are no mechanical or moving parts. Thermo electric module can provide noiseless, reliable and stable operation. Thermo electric coolers are used in cooling and refrigeration that is coolers in optoelectronic and portable electric food coolers. Thermo electric coolers are also used in temperature control application. Thermo electric generators are used to produce energy from waste heat. The thermo electric generator is very important in power generation from wireless communication and remote self-powered waste heat systems.

TEGs mathematical models are developed to simulate and analyze its performance TEG model using the Matlab / Simulink .

\section{THERMOELECTRIC GENERTOR}

Thermoelectric generators are converting thermal energy into electric energy. The electrical voltage is generated between two ends of two different metals they welded together maintaining at different temperature.

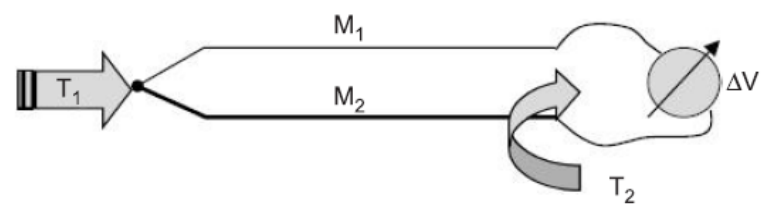

Fig.1. Thermo Electric Generator

Voltage developed:

$$
\Delta V=\alpha_{s} \Delta T
$$

Where: $\alpha_{\mathrm{s}}$ - Seebeck coefficient

$$
\begin{aligned}
& \Delta \mathrm{V}-\text { Voltage difference in Volts } \\
& \Delta \mathrm{T} \text { - Absolute temperature difference in Kelvin }
\end{aligned}
$$

Bulk effect of Seebeck coefficient can be determined by the following effects: Temperature difference of the TEG generates due to the difference in Fermi level. Bandgap distance also changes with temperature. With respect to function of temperature, the gradient of charge carriers changes the $\mathrm{n}$ and $\mathrm{p}$ type. In general, the diffusion coefficient of TEG is varied based on the function of temperature. By thermo diffusion, charge carriers switch from the warm side to the cold side. The charging carriers produce electric field. The effect of Seebeck is primarily used in thermocouples for temperatures ranging from -200 to $1600^{\circ} \mathrm{C}$.

Thermal conductivity is used to explain the thermal conduction phenomenon:

$\mathrm{Q}_{\mathrm{c}}=-\Delta \mathrm{TK}_{\mathrm{th}}$.

Let $\mathrm{K}_{\text {th }}$ is the module thermal conductivity and $\Delta \mathrm{T}=\mathrm{T}_{\mathrm{H}}-\mathrm{T}_{\mathrm{C}}$. The electric current flows through the module cause additional resistive heat loss. The total heat loss in thermo electric module is:

$\mathrm{Q}_{\mathrm{R}}=\mathrm{I}^{2} \mathrm{R}$

The output voltage of TEM is:

$\mathrm{V}=\Delta \mathrm{V}+\mathrm{IR}$

* Correspondence Autho

Dr.A Ramkumar *, Associate Professor ,Dept of Electrical \& Electronics Engg,, Kalasalingam Academy of Research and Education, KrishnanKoil, India. Email: ramkumar.manonmani@gmail.com

Sreekala P, Research Scholar, Dept of Electrical \& Electronics Engg, Kalasalingam Academy of Research and Education, KrishnanKoil, India. Email: p.sreekala3@gmail.com

Dr.K.Rajesh, Associate Professor Dept of Electrical \& Electronics Engg, Kalasalingam Academy of Research and Education, KrishnanKoil, India. Email: k.rajesh@klu.ac.in
A good thermo electric generator combines a High, low electrical resistance Seebeck coefficient R..The FOM (Figure of merit) is: 
$\mathrm{Z}=\frac{\alpha_{\mathrm{g}}{ }^{2}}{\mathrm{RK}_{\mathrm{th}}}$

\section{PARAMETER CALCULATION}

For calculating the parameter of thermo electric generator first considers cold and hot side temperatures. $\mathrm{W}_{\mathrm{L}}$ is the load power. The load resistance $\mathrm{R}_{\mathrm{L}}$ is compared to the thermoelectric module's internal resistance $\mathrm{R}$ and the load voltage $\mathrm{V}_{\mathrm{L}}$. By using the data sheet we can calculate the electrical parameters directly. The internal resistance of a TEG can be expressed as R and the $\alpha$ s (Seebeck coefficient).: $R=R_{L}=\frac{v_{L^{2}}}{W_{L}}$

$\propto_{\mathrm{s}}=\frac{2 \mathrm{~V}_{\mathrm{m}}}{\Delta \mathrm{T}}$

The efficiency of thermo electric generator is function of load. The $R L$ is known as $R_{L}=m R$ with $m$ being the $R_{L}$ and $R$ ratio of the thermoelectric module. The current through the TEG can be expressed as:

$I=\frac{\propto_{\mathrm{S}} \Delta \mathrm{T}}{[(1+\mathrm{m}) \mathrm{R}]}$

A TEG's thermal efficiency is defined as the ratio of the electrical output power to the heat input power, which can be expressed as:

$\eta_{t h}=\frac{I^{2}}{Q_{H}} R_{L}$

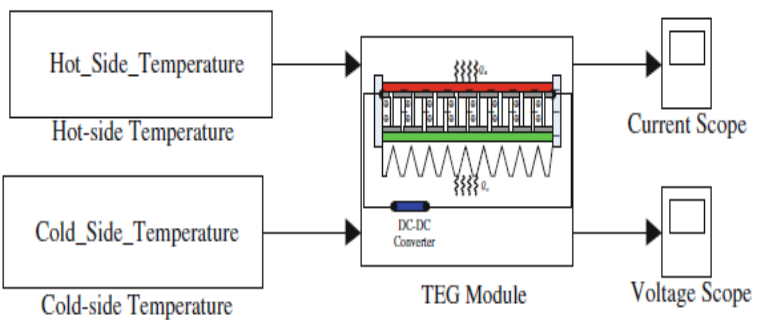

Fig.2. Model of Thermo Electric Generator

The TEG can be connected in three different methods they are described below.

\section{A. Series Configurations}

In series configuration the TEGs are connected in series. This configuration will increase the output voltage.

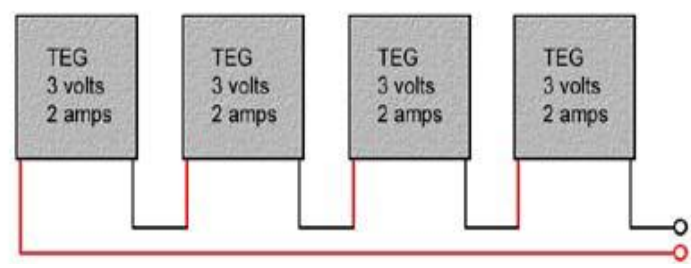

Fig.3. Series Configuration of Thermo Electric Generator

\section{B. Parallel Configuration}

In parallel configuration the TEGs are connected in parallel. This configuration increases the output current.

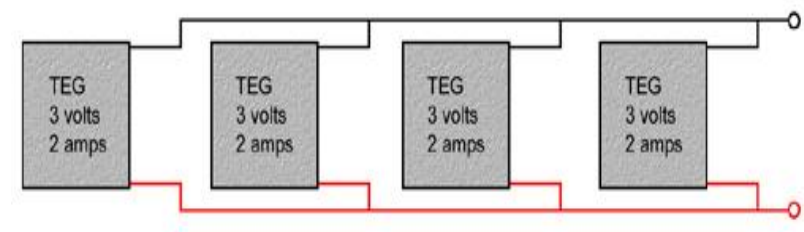

Fig.4. Parallel Configuration of Thermo Electric Generator

\section{Series-Parallel Configuration}

This configuration is the combination of parallel and series configuration of TEG. Those configuration increases the current and voltage capacity.

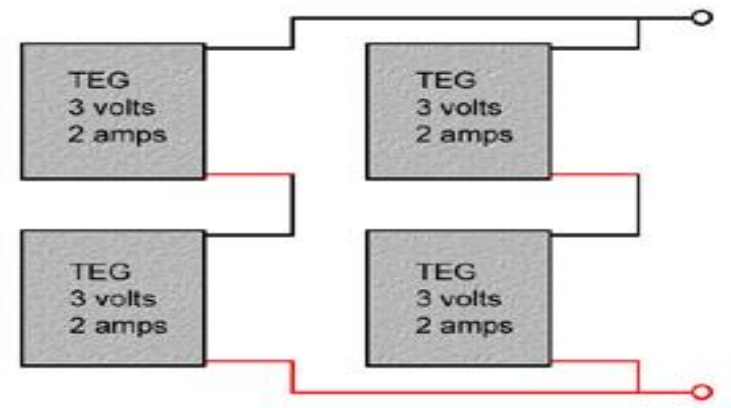

Fig.5. Series-Parallel Configuration of Thermo Electric Generator

The comparison of three configurations can be represented by using graph. From the graph series parallel configuration give better output than other two. For this reason, the configurations are selected.

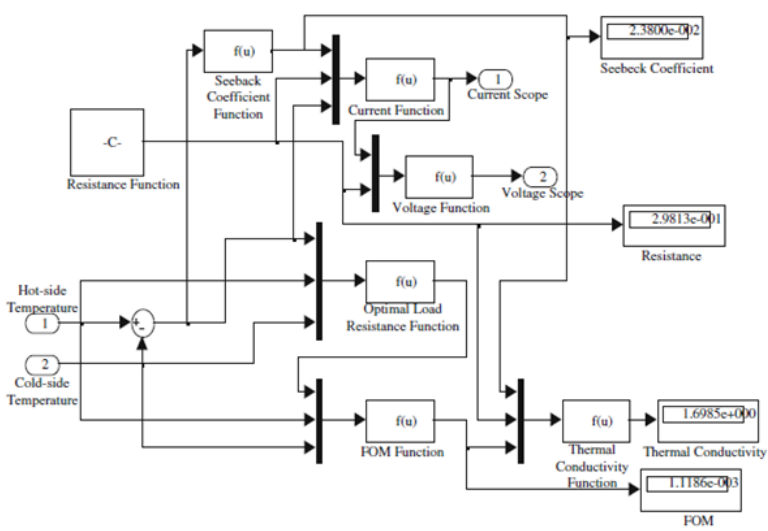

Fig. 6. Mathematical Model of TEG Subsystem

\section{SIMULATION RESULT}

Take HZ-20 thermo-electric unit, pick $\mathrm{TH}=2300 \mathrm{C}$, $\mathrm{TC}=300 \mathrm{C}, \mathrm{Wm}=19 \mathrm{~W}, \mathrm{Vm}=2.38 \mathrm{~V}$ and ${ }^{\eta_{\max }}=4.5 \%$ from their data sheet. $=0: 0238 \mathrm{~V} / \mathrm{K} ; \mathrm{R}=0: 2981 ; \mathrm{Kth} 1: 6985 \mathrm{~W} / \mathrm{K}$ and $\mathrm{Z}=0: 0011 \mathrm{~K}-1$.. The V-I characteristics and Power- Current characteristics are plotted. The thermo electric generator produces maximum power when $R_{L}$ is equal to $R$. This result summarizes that the maximum power is approximately $19 \mathrm{~W}$ at $\mathrm{I}=7,9832 \mathrm{~A}$ and $\mathrm{V}=2,3800 \mathrm{~V}$, and the average thermal efficiency is 4.5 percent when reaching approximately $7.2 \mathrm{~A}$. The data sheet values shown below are the energy Vs Temperature, Voltage Vs Temperature \& Efficiency Vs Temperature. 


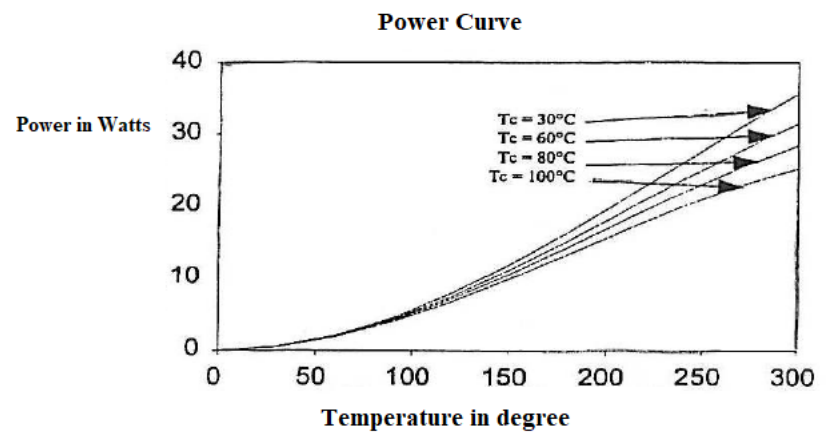

Fig. 7. Power Vs Temperature Curve

Voltage Curve

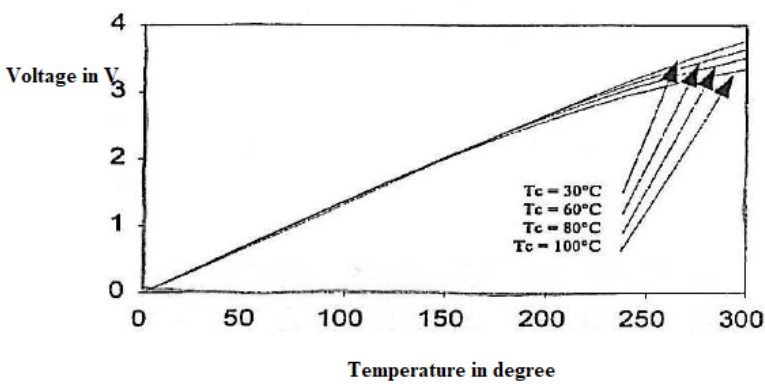

Fig. 8. Voltage $V_{s}$ Temperature Curve

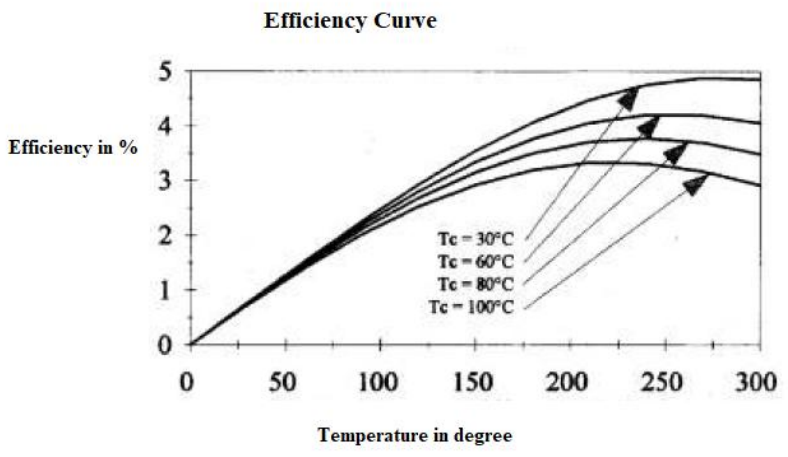

Fig. 9. Efficiency Vs Temperature Curve

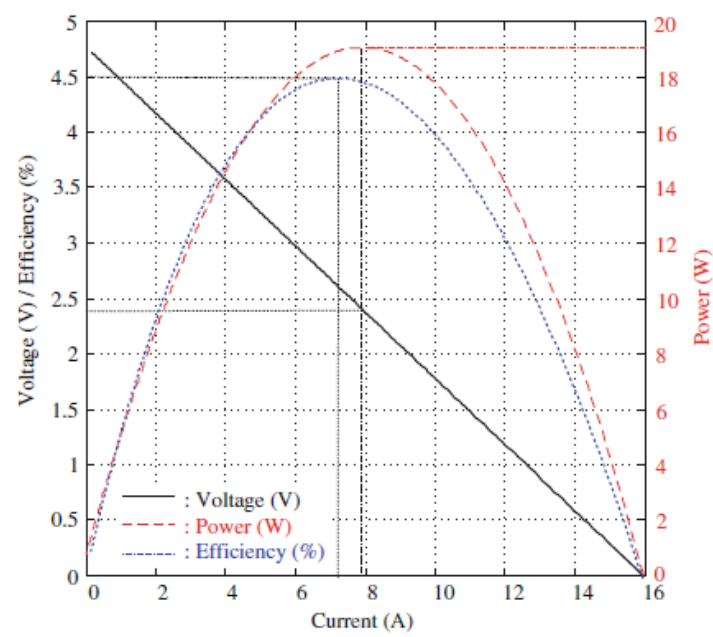

Fig 10. V-I and Power_I characteristics

\section{CONCLUSION}

Modelled the model of thermo electric generator. The maximum power is obtained when load resistance is equal to internal resistance. The results are validated. For getting more output power, voltage and current different connection combinations can be used. The hot surface properties of the module are $230^{\circ} \mathrm{C}\left(450^{\circ} \mathrm{F}\right)$ from the current-voltage curve and the cold surface of the module is $30^{\circ} \mathrm{C}\left(90^{\circ} \mathrm{F}\right)$. The value obtained from the graph is validated with simulation results.

\section{ACKNOWLEDGMENT}

The authors were very special thanks to management of Amaljyothi College of Engineering, Kerala, India And Kalasalingam Research \& Education Academy, Krishnakoil, Tamil Nadu, India to support the work.

\section{REFERENCES}

1. Ning Zhua, Takeru Matsuurab, Ryutaro Suzukib, Takashi Tsuchiyaa "Development of a Small Solar Power Generation Systembased on Thermoelectric Generator ", Energy Procedia, Vol. 52, No.1, pp. 651 658, 2014.J. Clerk Maxwell, A Treatise on Electricity and Magnetism, 3rd ed., vol. 2. Oxford: Clarendon, 1892, pp.68-73.

2. Huan-LiangTsai and .Jium-Ming Lin "Model building and simulation of thermo electric module using Matlab /Simulink" Journal of Electronic Materials Vol39,No 9,pp 2105-2111

3. J.A. Cha'vez, J.A. Ortega, J. Salazar, A. Turo', and M.J. Garci'a, IEEEIMTC.P. 2, 1019 (2000). doi:10.1109/IMTC.2000.848895.

4. S. Lineykin and S. Ben-Yakov, IEEE Power Electron. Lett. 3, 63 (2005). doi:10.1109/LPEL.2005.846822.

5. D. Mitrani, J.A. Tome', J. Salazar, A. Turo' , M.J. Garci'a, and J.A. Cha'vez, IEEE Trans.Instrum. Meas. 54, 1548 (2005).doi:10.1109/TIM.2005.851473.

6. C. Han, Z. Li, S.X. Dou, Chinese Science Bulletin, 59(18), 2073 (2014), "Recent Progress in Thermoelectric Materials."

7. Y. Pei, X. Shi, A. Lalonde, H. Wang, L. Chen and G. J. Snyder, "Convergence of Electronic Bands for High Performance Bulk Thermoelectrics”, Nature, 473, 66 (2011).

8. L. D. Zhao, S. Hao, S.-H. Lo, C.-I. Wu, X. Zhou, Y. Lee, H. Li, K. Biswas, T. P. Hogan, C. Uher, C. Wolverton, V. P. Dravid and M. G. Kanatzidis, "High Thermoelectric Performance via Hierarchical Compositionally Alloyed Nanostructures", J.Am. Chem. Soc., 135, 7364 (2013).

9. J. P. Heremans, V. Jovovic, E. S. Toberer, A. Saramat, K.Kurosaki, A. Charoenphakdee, S. Yamanaka and G. J. Snyder,

"Enhancement of Thermoelectric Efficiency in PbTe by Distortion of the Electronic Density of States", Science, 321, 554 (2008).

10. X. Shi, J. Yang, S. Bai, J. Yang, H. Wang, M. Chi, J. R. Salvador, W. Zhang, L. Chen and W. W.-Ng, "On the Design of High-Efficiency Thermoelectric Clathrates Through a Systematic Cross-Substitution of Framework Elements", Adv. Funct. Mater., 20, 755 (2010).

11. X. Shi, J. Yang, J. R. Salvador, M. Chi, J. Y. Cho, H. Wang,

S. Bai, J. Yang, W. Zhang and L. Chen, "Multiple-Filled Skutterudites: High Thermoelectric Figure of Merit through Separately Optimizing Electrical and Thermal Transports", J. Am. Chem. Soc., 133, 7837 (2011).

12. L.-D. Zhao, S.-H. Lo, Y. Zhang, H. Sun, G. Tan, C. Uher, C.

Wolverton, V. P. Dravid and M. G. Kanatzidis, "Ultralow Thermal Conductivity and High Thermoelectric F

\section{AUTHORS PROFILE}

Sreekala P was born in Kerala in May 1980. She took

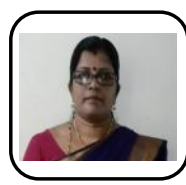

B Tech in Electrical and Electronics with first class from Rajiv Gandhi Institute of Technology Govt Engineering College Kottayam ,Kerala and MTech in Power Electronics and Power System from Amaljyothi College of Engineering Kanjirappally.Kottayam ,Kerala. She has memberships of MIE, Her research interests include Renewable energy (Solar -Thermal System),Biomedical Engineering, Electrical Machines and Power Systems 
Dr. A Ramkumar received the $\mathrm{PhD}$ degree from Kalasalingam Academy of Research and Education in the year of 2014. He received the ME (Power System)degree from faculty of Engineering and Technology. Annamalai University Chidambaram, Tamil Nadu, India in 2002 and received BE ( Electrical and Electronics Engineering) from Thiagarajar College of Engineering M K University, Madurai, Tamil Nadu in the year 1997. He has been working as an Assistant Professor in the department of Electrical and Electronics Engineering, Kalasalingam Academy of Research and Education , Srivilliputhur, Tamil Nadu since 2003. He is more than 19 years experience in the field of teaching. His research interests include Renewable Energy, Power System Planning, Power System Analysis, High Voltage DC Transmission Systems, Reactive Power Compensation, Flexible AC transmission Systems, Electrical Machines and Power system Automation. He is life member of ISTE and member of IE(I)

Dr. K Rajesh was born in Rajapalayam, TamilNadu,India in 1987.He received his UG degree in Electrical and Electronics Engineering from Anna University, Chennai in2008 and ME degree in Power System Engineering from Anna University, Thirunelveli TamilNadu,India in 2011. Since July 2011, he has been working as an Assistant Professor in the Department of Electrical and Electronics Engineering Kalasalingam Academy of Research and Education, Srivilliputhur, Tamil Nadu, India. He has attended several international conferences and he has been actively involving himself in research since 2013.Three of his research papers have been published in international journals and a research paper has been published in national journals. His current research includes generation expansion planning, energy planning, power system optimization and power system control. He has actively participated in various Faculty Development programs, Symposiums, orientation programs, workshops and national seminars. He has received Teaching Competency Award in the year 2015 and Research Competency Award in the Year 2015 \& 2017. He is a life member of ISTE and member of IE(I) 